\title{
Ask the Way From Those Who Have Walked It Before - Grandmothers' Roles in Health-related Decision Making and HIV Pre-exposure Prophylaxis (PrEP) Use Among Pregnant and Breastfeeding Women in Africa
}

Krishnaveni Reddy ( $\sim$ kreddy@wrhi.ac.za )

Wits Reproductive Health and HIV Institute https://orcid.org/0000-0002-3881-2704

Doreen Kemigisha

Makerere University - Johns Hopkins University (MUJHU) Research Collaboration

Miria Chitukuta

University of Zimbabwe College of Health Sciences Clinical Trials Research Centre

Sufia Dadabhai

Department of Epidemiology, Johns Hopkins Bloomberg School of Public Health Blantyre

Florence Mathebula

Wits Reproductive Health and HIV Institute (Wits RHI), University of the Witwatersrand, Faculty of Health Sciences

Siyanda Tenza

Wits Reproductive Health and HIV Institute (Wits RHI), University of the Witwatersrand, Faculty of Health Sciences

Thesla Palanee-Phillips

Wits Reproductive Health and HIV Institute (Wits RHI), University of the Witwatersrand, Faculty of Health Sciences

Julia Ryan

Women's Global Health Imperative (WGHI) RTI International

Nicole Macagna

FHI 360, Durham

Petina Musara

University of Zimbabwe College of Health Sciences Clinical Trials Research Centre

Ariane van der Straten

Women's Global Health Imperative (WGHI) RTI International and Center for AIDS Prevention Studies (CAPS), University of California San Francisco

Research

Keywords: Grandmother, Pregnancy, Breastfeeding, Dapivirine vaginal ring, oral PrEP

Posted Date: May 10th, 2021

DOl: https://doi.org/10.21203/rs.3.rs-459256/v1

License: (1) This work is licensed under a Creative Commons Attribution 4.0 International License. Read Full License 


\section{Abstract}

Background: HIV acquisition among pregnant and breastfeeding women in sub-Saharan Africa (SSA) and vertical transmission rates remain high despite established strategies for HIV prevention.

Methods: We explored grandmothers' (mothers/mothers-in-law) influence on pregnant and breastfeeding women's health-related decisions and their potential to support use of HIV prevention products utilizing qualitative data collected from grandmothers, HIV-uninfected, currently/recently pregnant or breastfeeding women and male partners of currently/recently pregnant or breastfeeding women during the MTN-041/MAMMA study.

Results: Grandmothers were described as important sources of information, playing both supportive and influencer roles, due to personal maternal experience and generational knowledge. Grandmothers expressed willingness to support pre-exposure prophylaxis (PrEP) use and agreed with other groups that this decision should be made by women themselves and/or with partners.

Conclusion: With the right framing and approach, grandmothers' supportive roles can optimise uptake and adherence to biomedical HIV prevention and reduce HIV acquisition among pregnant and breastfeeding women in these communities.

\section{Introduction}

HIV incidence rates in pregnant and postpartum sub-Saharan African women are unacceptably high. A meta-analysis reported 4.7 cases per 100 person-years during pregnancy and 2.9 cases per 100 person-years postpartum, both of which were similar or higher than HIV incidence among female sex workers and HIV-serodiscordant couples (1). Despite established prevention strategies like provision of condoms, partner testing, male circumcision, early initiation of antiretroviral therapy (ART), harm reduction services for women who inject drugs and management of sexually transmitted infections (STI) (2), HIV acquisition during these maternal periods and subsequent vertical transmission remain on the rise $(3,4)$. Many available HIV prevention strategies rely on partner acceptance and participation; however, the ongoing HIV incidence highlights the necessity for female-initiated prevention options.

Daily oral pre-exposure prophylaxis (PrEP) consisting of tenofovir disoproxil fumarate/emtricitabine (TDF/FTC) in a single pill, fixed-dose combination known as Truvada ${ }^{\mathrm{T} M}$, has been available in parts of sub-Saharan Africa (SSA) since 2016 with rollout targeting prioritized populations (i.e., sex workers, men who have sex with men, serodiscordant couples, adolescent girls and young women). Per World Health Organization (WHO) guidelines, PrEP use may continue during pregnancy and breastfeeding if a woman remains at substantial risk of HIV infection (2). In July 2020, the European Medicines Agency issued a positive opinion for the vaginal ring containing the antiretroviral (ARV) drug dapivirine as an additional prevention option for adult cisgender women in developing countries (5). This was followed by the World Health Organization's (WHO) recommendation, on 26 January 2021, of the vaginal ring as a new choice for HIV prevention for women at substantial risk of HIV infection (6). The dapivirine vaginal ring, referred to as the ring hereafter, requires only monthly replacement, and was shown to protect women from HIV-1 in two pivotal phase III trials and their subsequent open label extension studies (7-10). Studies to determine the safety and acceptability of the ring during pregnancy and breastfeeding are ongoing (11).

The effectiveness of these oral and vaginal PrEP strategies are driven by user adherence $(12,13)$, which can be challenging (14-16), especially with daily dosage. As such, innovative strategies to support adherence are warranted, including in pregnant and breastfeeding women, an important population for PrEP. Grandmothers play a central role in the sub-Saharan African family, as sources of information, wisdom and comfort. They are seen as owners of traditional knowledge and cultural history and are important figures in pregnant and breastfeeding women's lives (17), with evidence that they can positively influence maternal knowledge and support exclusive breastfeeding (18-20). Nevertheless, grandmothers have not been studied as influencers for use of HIV prevention options among women generally, or specifically for those pregnant and breastfeeding. We address this gap, by drawing on qualitative data gathered during the multi-site MTN-041/MAMMA study in SSA (21). We sought to explore grandmothers'/elders' views on oral PrEP and the vaginal ring, their roles in informing decision making and their support of the use of these products by their pregnant and breastfeeding daughters/daughters-in-law.

\section{Methods}

Study Design: MAMMA (Microbicide/PrEP Acceptability among Mothers and Male Partners in Africa) was conducted between May and November 2018 in four settings: Malawi (Blantyre); South Africa (Johannesburg); Uganda (Kampala) and Zimbabwe (Chitungwiza). The study included the conduct of single-sex focus group discussions (FGDs) with individuals independently recruited into one of three groups: a) HIV-uninfected (by self-report) women aged $\geq 18-40$ who were recently (within the previous two years) or currently pregnant or breastfeeding b) Men aged $\geq 18$ whose partners were recently or currently pregnant or breastfeeding and c) maternal and paternal grandmothers whose daughters or daughters-in-law were recently or currently pregnant or breastfeeding. Detailed methods and primary results for this study have been previously published (21).

Study population and settings: Participants were recruited from urban and peri-urban community settings, including street outreach, outreach at construction sites (men only), at antenatal and postnatal clinics (women only), as well as through word of mouth and community advisory board member referral. Malawian participants were recruited within Blantyre District, the country's centre of commerce and industry. South African participants were recruited within Hillbrow, an inner-city residential neighbourhood of Johannesburg that serves as a port of entry for migrants and immigrants from the townships, rural areas and the rest of Africa and as such nurtures a highly transient population. Ugandan participants were recruited within Kampala, the capital city and main centre of cash flow for Uganda's economy. Zimbabwean participants were recruited from Chitungwiza, a dormitory town to the south of Harare, and the peri-urban settlements surrounding it.

Procedures: All participants provided written informed consent before demographic information was individually collected through interviewer-administered questionnaires in local languages (Chichewa in Malawi, Zulu or English in South Africa, Luganda in Uganda and Shona in Zimbabwe). A behavioural 
assessment was also completed with the pregnant and breastfeeding women and male participants. Gender-matched trained local social scientists fluent in local languages facilitated the FGDs using semi-structured guides. Participants were requested to use pseudonyms to protect their identities. Topics discussed included HIV risk perceptions, cultural beliefs and practices relating to pregnancy and breastfeeding, health-related decision making, key influencers and interest in two new HIV prevention products while pregnant or breastfeeding: daily oral PrEP pills and the monthly vaginal ring (7, 22). Participants viewed a 4minute educational video (in the local language) and handled sample products immediately prior to discussing these new HIV prevention options. FGDs were audio recorded and transcribed/translated into English, as applicable.

\section{Analysis:}

Analysis workshops were held for all site staff involved in qualitative data collection to conduct a preliminary analysis of the data; workshops directly informed the iterative development of the codebook used to systematically analyse all qualitative data as described previously (21, 23). The codebook followed a socio-ecological framework. For this analysis, data coded for "PILL", "RING" and "PREFERENCE" were extracted from Grandmother FGD transcripts and stratified by country. Data coded for the "FAMILY" code were extracted from all FGDS and stratified by participant type (i.e., grandmothers, pregnant/breastfeeding women and male partners) in addition to country. Data reports were then thematically analysed by representatives of the four sites into analytical memos that were reviewed by the writing team biweekly to discuss coding questions and emerging themes.

Ethics statement: The study protocol was approved by the Western Institutional Review Board (IRB) located in Olympia, Washington, USA as well as local IRBs at each of the study sites and was overseen by the regulatory infrastructure of the U.S. National Institutes of Health and the Microbicide Trials Network (MTN).

\section{Results}

Overall, 197 individuals were screened and 196 joined one of the 24 FGDs conducted (Table I). This included 68 grandmothers, 65 pregnant or breastfeeding women and 63 male partners of pregnant or breastfeeding women (referred to as male partners hereafter).

Demographic data are presented in Table II by participant group and country. The mean age of grandmothers in the study was 50 years (min 36 , max 69 ), $21 \%$ $(\mathrm{N}=14)$ were single, $43 \%(\mathrm{~N}=29)$ were married or living with their partners and $38 \%(\mathrm{~N}=26)$ were divorced, separated or widowed. Most grandmothers lived with their children $(81 \%, N=55)$. The mean age of pregnant and breastfeeding women was 27 years ( $\min 19, \max 40)$ and $77 \%$ were married or living with their partners $(\mathrm{N}=50)$. The mean age of male partners was 31 years ( $\min 19$, max 54$)$ and $81 \%$ were married or living with their partners $(\mathrm{N}=51)$. The South African pregnant and breastfeeding women and male partners differed from those in the other settings with regards to marital status and living arrangements. Most were single ( $93 \%$ of pregnant or breastfeeding women and $92 \%$ of male partners) and majority $(67 \%$ of pregnant or breastfeeding women [ $\mathrm{N}=10]$ and $58 \%$ of male partners [ $\mathrm{N}=7]$ ) were living with adult family members including parents and siblings. In contrast, most pregnant and breastfeeding women and male partners in the remaining settings were married (83-94\%) and living with their spouse or primary partner (79-94\%). Additionally, lower numbers of South African participants reported earning an income and $60 \%$ of South African grandmothers $(\mathrm{N}=12)$ were single (Table II).

\section{Views on influential decision-makers during pregnancy and breastfeeding}

Pregnant and breastfeeding women were assessed about their views on who, besides themselves, has the most influence on health-related decisions during these periods (Table III). The majority in all settings besides South Africa indicated that the father of the baby had the most influence during pregnancy (60$88 \%$ ) and breastfeeding (53\%-92\%). However, among South African women, their mothers (40\%) had more influence than the baby's father (20-27\%).

FGDs revealed similar findings to the behavioural assessment, with household composition and living arrangements appearing to impact who the key decision-making influencers were. South African grandmothers, pregnant and breastfeeding women, and male partners emphasized that it is the elders (grandmothers) who make decisions, especially in cases where the pregnant or breastfeeding women live with their mothers or returned home to their mothers to give birth (even if married). Grandmothers help look after the baby and therefore have authority:

The decision we take or follow as the family are more important that those from the clinic because as a nursing mother you live, and sleep with your granny and mother in the house, and they help look after the baby, so you must listen to them anything you do. [Dineo, Grandmother, 58, South Africa]

Decision making may also be impacted by lobola (payment a male partner or head of his family gives to the woman's family in gratitude for allowing the marriage) or damages (payment made if a woman is impregnated before marriage to show that the male partner's family accepts the baby as their own) as expressed by male partners and pregnant or breastfeeding women:

We grew up knowing that if a man is not married and has not paid the damages the baby belongs to the mother's family. He has no choice if he has not paid for damages; he has to understand that my family said this because it is their baby. You must sit down with him and explain to him as the father of the baby that your family says that this or that must be done to the baby. [Nonhlanhla, Breastfeeding woman, 34, South Africa]

In the settings outside South Africa, grandmothers were generally not considered decision makers, with a few exceptions related to non-payment of lobola, living in close proximity and because the women may behave irrationally (e.g., having variable moods, getting upset) during pregnancy and need someone to decide on their behalf:

I would think it is that person who is near you, it can be your husband, your mother and the health worker because pregnant women sometimes behave funny. [Esther, Pregnant woman, 22, Uganda]

Grandmothers tended to portray their daughters and daughters-in-law as naïve during maternal times, especially if it was a first pregnancy, seeing themselves in a privileged position to support and educate them due to their own maternal experiences and expertise and as custodians of knowledge passed down 
through generations:

In Zulu there is a saying that say, "Ask the way from those who have walked it before", even if people don't have mothers, you can see from neighbours or you can ask from your aunt or any elder. [Sindiswa, Grandmother, 36, South Africa]

This included advising on cultural practices, correct food and drink, and health seeking behaviour. Grandmothers in Malawi and South Africa said they also guided their daughters/daughters-in-law in sexual matters (see Table IV).

Overall, pregnant and breastfeeding women and male partners confirmed the value of grandmothers' traditional knowledge and advice, ascribing them with legitimacy since they had healthy pregnancies before allopathic medicine became the standard. A reliance on maternal grandmothers was emphasized in many instances:

But if you notice our mothers grew up preferring traditional doctors than medical doctors and they went through all this process without consulting [medical] doctors, of which their pregnancy and their children were healthy. [Asanda, Pregnant woman, 26, South Africa]

Given the importance of grandmothers in providing cultural information and traditional wisdom to pregnant and breastfeeding women, we explored grandmothers' willingness to support their pregnant or breastfeeding daughters/daughters-in-law in the use of PrEP in the future as well as their views on the ring and oral PrEP for HIV prevention, including the likelihood of cultural acceptance or resistance to these products.

\section{Grandmothers' willingness and motivation to support HIV prevention product use}

Across all groups, the majority views about HIV testing and prevention related decision making was that it is a decision made by pregnant or breastfeeding women alone or together with their partners with emphasis placed on openness and tolerance for health seeking behaviours during these times:

When it comes to making decisions in a family, it is good to decide together as husband and wife...the most important thing is that there should be openness in the family... there is need to make decisions together not each one by themselves. [Davie, Male partner, 24, Malawi]

Many grandmothers also thought that involving the male partner in such decisions was key, as the baby is made jointly:

You are not mistaken about the man, you are not mistaken at all, it takes two to tango, HIV is not for an individual person, and it is for 2 people. It like a baby is made by 2 people, so they must [decide on HIV prevention product use together. [Dineo, Grandmother, 58, South Africa]

Pregnant and breastfeeding women additionally indicated that grandmothers should be kept out of decisions to use HIV prevention products because of cultural taboos that forbid discussing sexual issues with your mother/in-law, and issues of confidentiality among other matters:

Sometimes you find that mothers might fail to keep the matter confidential, yet partners are able to do so. I think it should be between us; the husband and the wife. [Esther, Pregnant woman, 22, Uganda]

However, they thought grandmothers could be involved in HIV prevention product use in a supportive role if this was disclosed to them:

It depends if you want to tell them because at the end of the day it is your life at risk so if you have to inform them already that you are taking either the vaginal ring or oral PrEP that I am taking this because of this. If they are interested, they will support you if they are not they won't. [Apple, Pregnant woman, 24, South Africa]

Grandmothers themselves explained their advisory role in a range of domains during their daughters' pregnancy and lactation (see Table IV), and also expressed a high level of willingness to support them to use both HIV prevention methods in a bid to protect them, their grandchildren and, indirectly, their sons from HIV.

They are all your children because your daughters-in-law sleeps with your son, if she is unfaithful and gets infected, she is going to infect your son also. [Pinki, Grandmother, 43, South Africa]

They expressed that a good relationship with the daughter/daughter-in-law is important for this and that choice of product would depend on what was right for the daughter or daughter-in-law:

It will depend on the relationship that is between the mother/mother-in-law and the pregnant/breastfeeding woman. If they are open to each other.... It is important to sit down with her and talk to her with patience until she understands but not forcing her, let her make a choice. [Evelyn, Grandmother, 47, Malawi]

The main motivation to support HIV prevention product use was to prevent a disease with no cure, caused in many cases by male partner promiscuity and dislike of condoms and resulting in the loss of children to HIV. Additional reasons cited included the responsibility of having to care for an HIV infected daughter/daughter-in-law and infant and continuously high HIV rates, especially among younger women. Grandmothers indicated they could offer financial, emotional and instrumental support to ensure their daughter's/daughter-in-law's high adherence to PrEP. For oral PrEP it included daily reminders, ensuring that she takes her pills with her when she goes out or travels or providing the pills themselves to ensure she takes it daily.

I would like her to take those drugs every day because some people forget or at times they are negligent about their lives so if she lives in next to me I would like to give her the pills by myself. We may agree to a certain time that at such a time I will knock at your door so that you take it [pill]. [Esther, Grandmother, 44, Uganda] 
Support for ring use included facilitating access to the ring and ensuring it is inserted appropriately:

I would accompany her to go and change the ring and if she can't, she can send me to fetch it for her, when I get home with it I would say let's go the bedroom I have your parcel and see her inserting it. [Dineo, Grandmother, 58, South Africa]

\section{Grandmothers' views on new biomedical prevention tools}

Overall, grandmothers embraced the concept of new HIV prevention products for pregnant and breastfeeding women, beyond condoms:

The advantage with these products is that they contain medicines that can kill the virus unlike a condom which when worn incorrectly can burst then you get HIV. [Mbuya Shava, Grandmother, 43, Zimbabwe]

Grandmothers expressed relief that options to protect both their daughters and their unborn grandchildren were forthcoming, although establishing the safety of these would be crucial:

I would be happy for our daughters to use it [oral PrEP pill] at least they would be protected from their partners, and their babies would be.... Now the issue of health; I mean the risk of how their bodies would tolerate the tablet. The side effects are my concerns because the tablets must be consumed. [Mamorena, Grandmother, 58, South Africa]

Indeed, grandmothers expressed several concerns which may impact future endorsement of these products (see Table V). Ring concerns included its size, whether it would enlarge the vagina and be painful to the woman using it, side effects for the foetus or infant from the medication or causing newborn injuries during delivery.

I was just thinking that if it remains inside it can hurt the baby during birth. Maybe the birth canal would be too narrow. [Mbuya vaPinky, Grandmother, 48 , Zimbabwe]

Several partner-related concerns were raised too:

Because once he feels the ring, that is when he might want to know what's inserted inside and start accusing the wife of prostitution. When the ring is actually being helpful. [Mbuya Zvakanaka, Grandmother, 63, Zimbabwe]

For oral PrEP, HIV risk related to forgetting to take the pills, HIV stigma, side effects to the mother and safety of the developing foetus, including potential for miscarriage in the first trimester were indicated (Table V). Miscarriage concerns were related to medication bitterness in Malawi, Uganda and Zimbabwe:

Our parents used to say that a pregnant woman should not take drugs that are bitter because some drugs can cause abortion. It all depends on how strong one's blood is. Some women have strong blood and some have weak blood. [Evelyn, Grandmother, 47, Malawi]

When elaborating on the stigma associated with taking ARVs as for HIV treatment, some added that having HIV these days was not seen as stigmatizing as it was previously, as the disease is commonplace, impacts everyone to some degree and is accepted by many. There was a general feeling that the health of their daughters/daughters-in-law should be prioritized and should override worry related to stigma:

It's high time that you don't focus on checking who is saying what about your health, it is up to you whether your health stays safe no matter who says what. [Pinki, Grandmother, 43, South Africa]

Grandmothers acknowledged that if these products have been well researched and tested, the safety concerns they raised could be overcome with the correct information from healthcare providers (HCPs) who are best positioned to guide pregnant and breastfeeding women on prevention method use:

These pills have been examined and tested first, it's not like they will just come from the blues and get imposed on us. So, teachings are important, like we are taught when we go to clinics. So, people should be taught until they come to know and accept the new products so that no one will think that they will be affected negatively by them. [Mbuya Peter, Grandmother, 45, Zimbabwe]

The ring appeared to be favoured by grandmothers over oral PrEP given its discreteness, especially without the partner knowing, its monthly duration and hence, lower use burden (less likely to forget to use). It also avoids the need to ingest, which could cause side effects for the pregnant mother and foetus:

Because once you insert the ring you spend the whole month with it without any challenges but with the daily oral PrEP people will forget. [Mbuya Tsitsi, Grandmother, 42, Zimbabwe]

There was a general view that pregnant and breastfeeding women should be able to protect themselves and both products were referred to as a "women's defence" to shield infection brought into their relationship by male partners, particularly in situations where women do not have decision making power (e.g., cannot negotiate condom use):

There is a need to quietly protect yourself since it is culturally accepted that a man can just find someone to have sex with and they do it without using protection. At home wives do not use protection, so it will be good if I protect myself because if he gets infected, I will block the virus and he will have his own virus. [Mbuya Rutendo, Grandmother, 44, Zimbabwe]

Grandmothers' views on cultural misalignments with ring and oral PrEP

Page 5/13 
Although a minority concern was raised in Malawi, Uganda and Zimbabwe that pregnant women should not take bitter drugs that may provoke miscarriage, most grandmothers did not feel that the bitterness of oral PrEP was culturally taboo as with other western medication used during pregnancy (e.g., Fansidar for malaria) and because traditional medicines can also be bitter. The impact of the drug was in some cases related to the weakness of the pregnant or breastfeeding women's bodies as well as how far along the pregnancy was:

That drug depends on the body weakness that one has because during my first pregnancy I took bitter medicine but I had no side effects. The condition was the same and I was jumping around and it was mululuuza [herb taken for fever] but I had no side effects. And it was during the first three months. [Meisha, Grandmother, 45, Uganda]

Interactions between traditional vaginal products and the ring (possibly impacting efficacy of the ring) were raised among some grandmothers but they indicated they would discourage their pregnant and breastfeeding daughters/daughters-in-law from these practices when using the ring so that they may be protected from HIV.

I will tell her to use the ring and do birth preparation practices that does not require the use of herbs. She will use the ring to prevent HIV and stop using herbs. I will encourage her to use the soap only because the soap does not contain any drug that can cause some side effects. [Mbuya Rarara, Grandmother, 36, Zimbabwe]

The majority of grandmothers interviewed did not expect oral PrEP or the ring to conflict with cultural beliefs and practises around pregnancy and breastfeeding. One grandmother likened HIV negative pregnant women taking oral PrEP to HIV positive pregnant women taking ARVs, which is widely accepted:

There is no cultural belief that can prevent a pregnant woman from taking Truvada because the Government has a policy that all pregnant women who are found to be HIV positive at the ANC, when the pregnancy is term, they are given drugs to take in order to prevent the unborn baby from contracting HIV and AIDS. So I feel this drug called Truvada is like the same as that drug [for treatment]. [Tadala, Grandmother, 40, Malawi]

Overall, grandmothers thought that HIV prevention is the priority, different illnesses require different approaches and, as there are no traditional medications available to stop HIV, the ring and oral PrEP pills are the tools to achieve this key goal:

I don't see why there should be a clash because there's nothing that can prevent HIV except for things like these, the ring and the pills. [Yellow, Grandmother, 43, South Africa]

\section{Discussion}

We used qualitative data collected during the MAMMA/MTN-041 study to explore grandmothers' views on the ring and oral PrEP for HIV prevention, their willingness to support their pregnant and breastfeeding daughters'/daughters'-in-law use of these products, as well as their supportive roles in the healthrelated decision making of their pregnant and breastfeeding daughters/daughters-in-law as a strategy to reduce HIV acquisition among this population in SSA. Views of pregnant and breastfeeding women and male partners, from the multi-site settings where MAMMA was implemented, with regards to grandmothers' roles aligned with views expressed by grandmothers.

Multi-stakeholder perspectives revealed that grandmothers were considered a source of information and support to their daughters/daughters-in-law during these maternal times. This was attributed to grandmothers being custodians of traditional and cultural practices and knowledge passed down through generations and having had successful pregnancies themselves in the past. Grandmothers in South Africa were described as having more decision-making capacity by all groups, compared to Malawi, Uganda and Zimbabwe, and this was attributed to living arrangements, household composition and non-marital ties with male partners. Indeed, a majority of South African pregnant and breastfeeding women reported being single and/or living in a household with their mothers or other adult relatives and indicating their mothers and other elders or siblings as having more decision-making influence.

Grandmothers and pregnant or breastfeeding women across all settings recognized that decisions and choice around HIV prevention products should be that of the women themselves or both partners together. The potential supportive role of grandmothers in HIV prevention product use was endorsed in all settings, but more strongly in South Africa, although this was most likely linked to the fact that the pregnant or breastfeeding woman would be living/staying in their parents' home. Grandmothers themselves expressed a high level of willingness to support pregnant and breastfeeding women in their use of these products as they felt women should be able to protect themselves and because by doing so, they would be helping to protect not only their daughters but the whole family (21). Grandmothers appeared to readily understand the purpose of the ring and oral PrEP with only a brief introduction (short video and sample product handling) and saw their value in protecting their children and unborn grandchildren. They recognized HIV as a disease with no cure, caused in many cases by male partner promiscuity and dislike of condoms and resulting in added responsibility of taking care of HIV infected children and grandchildren, eventual loss of those HIV infected and grandmothers' return to a mothering role in their old age. This is in keeping with published data indicating grandmothers' roles as caregivers for their grandchildren orphaned by HIV, a frequent occurrence of the pandemic in SSA $(24,25)$. As such, grandmothers appeared relieved that new PrEP products are or will be available soon. While the ring appeared to be favoured over the pills, concerns were raised about both products, many of which were reflective of known concerns of oral and vaginal PrEP users among multiple populations or trial settings (26, 27). Grandmothers, however, recognized that these products have been researched and tested and that these concerns could be overcome by thorough education and accessing these through HCPs, who are trained to counsel pregnant and breastfeeding women on their proper use. Cultural conflicts were not expected to be a major issue, with HIV prevention being prioritized over cultural practices in some instances. It is therefore possible that if their supportive roles can be successfully harnessed, grandmothers may have the potential to promote HIV prevention product use among their pregnant and breastfeeding daughters and daughters-in-law during 
maternal times and this could enhance uptake and adherence to these products. Grandmothers have previously been engaged in efforts to reduce unintended pregnancy (28) as well as HIV acquisition(29) and their support has been shown to be an important direction for prevention.

The MAMMA study had several limitations. Firstly, while male partners and grandmothers were recruited from various urban and peri-urban community settings, which may best reflect overall community views, pregnant and breastfeeding women were recruited mainly from antenatal and postnatal clinics and, as such, represent views of women who have access to healthcare services. It is possible that pregnant and breastfeeding women without healthcare services may rely more on family and possibly elders in terms of their decision making. Secondly, participants were product naïve which meant that they had had no direct experience with the products when discussing them. This was purposefully done to elicit oral PrEP and ring discussion and ascertain perspectives representative of the product naïve communities into which these products are being or will be introduced for rollout. Thirdly, it was difficult to ascertain whether some responses during the discussions were related to mothers or mothers-in-law specifically, as the terminology was interchanged with the more generic "grandmother" term. Fourthly, responses may have been swayed by social desirability bias as participants were interviewed in clinic settings. Finally, qualitative data analysis is interpretative; however, representatives from each setting were involved during analyses and biweekly meetings to discuss coding, emerging themes and to maximize consensus. While these limitations may have impacted our analysis to some extent, the multi-country sample and discussions that were mostly aligned across the different settings add strength to our findings.

\section{Conclusion}

Grandmothers across the four study settings expressed interest in oral PrEP and the ring for HIV prevention and a willingness to support their use by their pregnant or breastfeeding daughters and daughters-in law to protect their children and grandchildren. Both pregnant and breastfeeding women and male partners, in addition to grandmothers themselves, saw grandmothers as having a supportive and sometimes key influencer role in the health-related decision making of pregnant and breastfeeding women due to their own prior parity experience and their knowledge of traditional/cultural practices that could also be leveraged. Although the intensity of these roles differed by setting, with the right framing and approach, grandmothers' supportive influence may be extended to uptake and adherence to HIV prevention options and further contribute to the decline in HIV acquisition among pregnant and breastfeeding women in these communities.

\section{Declarations}

- Ethics approval and consent to participate: The study was approved by the Western Institutional Review Board (IRB) located in Olympia, Washington, USA as well as local IRBs at each of the study sites.

- Consent for publication - Consent for publication was provided via the study consent forms.

- Availability of data and material - The datasets analysed during the current study are available from the corresponding author on reasonable request.

- Competing interests - The authors declare that they have no competing interests.

- Funding - Division of AIDS, US National Institute of Allergy and Infectious Diseases, US Eunice Kennedy Shriver National Institute of Child Health and Human Development, US National Institute of Mental Health, US National Institutes of Health.

- Author contributions: KR and AV designed the study. KR, DK, MC and SD performed data analysis on code reports for each site, JR provided quantitative data. KR wrote the first draft of the manuscript. AV reviewed and edited the first manuscript draft. DK, MC, SD, JR, FM, ST, TP, NM and PM provided additional review and edits to the manuscript.

- Acknowledgments: The authors are grateful to the study participants for their participation and dedication. The authors thank the research site study team members, the MTN-041/MAMMA Protocol Management team, the MTN Leadership Operations Center, Women's Global Health Imperative (WGHI) RTI International and FHI 360 for their contributions to data collection. The MAMMA trial was designed and implemented by the Microbicide Trials Network (MTN). The MTN is funded by the National Institute of Allergy and Infectious Diseases (UM1AI068633, UM1AI068615, and UM1Al106707), with cofunding from the Eunice Kennedy Shriver National Institute of Child Health and Human Development and the National Institute of Mental Health, all components of the US National Institutes of Health. The content is solely the responsibility of the authors and does not necessarily represent the official views of the National Institutes of Health. The rings and oral PrEP used as sample products were developed and supplied by the International Partnership for Microbicides (IPM) and Gilead Sciences respectively.

\section{References}

1. Drake AL, Wagner A, Richardson B, John-Stewart G. Incident HIV during pregnancy and postpartum and risk of mother-to-child HIV transmission: a systematic review and meta-analysis. PLoS Med. 2014;11(2):e1001608.

2. World Health Organization Technical Brief: Preventing HIV during Pregnancy and Breastfeeding in the Context of PrEP online2017 [Available from: https://apps.who.int/iris/bitstream/handle/10665/255866/WHO-HIV-2017.09-eng.pdf?sequence=1.

3. Graybill LA, Kasaro M, Freeborn K, Walker JS, Poole C, Powers KA, et al. Incident HIV among pregnant and breast-feeding women in sub-Saharan Africa: a systematic review and meta-analysis. AIDS. 2020;34(5):761-76.

4. Thomson KA, Hughes J, Baeten JM, John-Stewart G, Celum C, Cohen CR, et al. Increased Risk of HIV Acquisition Among Women Throughout Pregnancy and During the Postpartum Period: A Prospective Per-Coital-Act Analysis Among Women With HIV-Infected Partners. J Infect Dis. 2018;218(1):16-25.

5. European Medicines Agency (EMA) approval of the dapivirine ring for HIV prevention for women in high HIV burden settings Online [Available from: https://www.who.int/news-room/detail/24-07-2020-european-medicines-agency-(ema)-approval-of-the-dapivirine-ring-for-hiv-prevention-for-women-inhigh-hiv-burden-settings. 
6. WHO recommends the dapivirine vaginal ring as a new choice for HIV prevention for women at substantial risk of HIV infection Online: World Health Organization; 2021 [Available from: https://www.who.int/news/item/26-01-2021-who-recommends-the-dapivirine-vaginal-ring-as-a-new-choice-for-hivprevention-for-women-at-substantial-risk-of-hiv-infection\#: :text=WHO\%20today\%20recommended\%20that $\% 20$ the,the $\% 20$ risk\%20of\%20HIV\%20infection.

7. Baeten JM, Palanee-Phillips T, Brown ER, Schwartz K, Soto-Torres LE, Govender V, et al. Use of a Vaginal Ring Containing Dapivirine for HIV-1 Prevention in Women. N Engl J Med. 2016;375(22):2121-32.

8. Nel A, van Niekerk N, Kapiga S, Bekker L-G, Gama C, Gill K, et al. Safety and Efficacy of a Dapivirine Vaginal Ring for HIV Prevention in Women. N Engl J Med. 2016;375(22):2133-43.

9. International Partnership for Microbicides. Final Results of Open-label Study of IPM's Dapivirine Vaginal Ring Show Increased Use and Suggest Lower Infection Rates Compared to Earlier Phase III Study 2019 [updated 11-14 June 2019. Available from: https://www.ipmglobal.org/content/final-resultsopen-label-study-ipm\%E2\%80\%99s-dapivirine-vaginal-ring-show-increased-use-and-suggest.

10. Baeten JM, Palanee-Phillips T, Mgodi NM, Mayo AJ, Szydlo DW, Ramjee G, et al. Safety, uptake, and use of a dapivirine vaginal ring for HIV-1 prevention in African women (HOPE): an open-label, extension study. Lancet HIV. 2021;8(2):e87-e95.

11. Microbicide Trial Network Studies Online: Microbicide Trial Network; 2020 [Available from: https://www.mtnstopshiv.org/news/studies.

12. Burns RN, Hendrix CW, Chaturvedula A. Population pharmacokinetics of tenofovir and tenofovir-diphosphate in healthy women. J Clin Pharmacol. 2015;55(6):629-38.

13. Brown ER, Hendrix CW, van der Straten A, Kiweewa FM, Mgodi NM, Palanee-Philips T, et al. Greater dapivirine release from the dapivirine vaginal ring is correlated with lower risk of HIV-1 acquisition: a secondary analysis from a randomized, placebo-controlled trial. J Int AIDS Soc. 2020;23(11):e25634.

14. Celum CL, Delany-Moretlwe S, Baeten JM, van der Straten A, Hosek S, Bukusi EA, et al. HIV pre-exposure prophylaxis for adolescent girls and young women in Africa: from efficacy trials to delivery. J Int AIDS Soc. 2019;22 Suppl 4(Suppl Suppl 4):e25298.

15. Sidebottom D, Ekström AM, Strömdahl S. A systematic review of adherence to oral pre-exposure prophylaxis for HIV - how can we improve uptake and adherence? BMC Infect Dis. 2018;18(1):581.

16. Montgomery ET, Stadler J, Naidoo S, Katz AWK, Laborde N, Garcia M, et al. Reasons for nonadherence to the dapivirine vaginal ring: narrative explanations of objective drug-level results. AIDS. 2018;32(11):1517-25.

17. Bezner Kerr R, Dakishoni L, Shumba L, Msachi R, Chirwa M. "We grandmothers know plenty": breastfeeding, complementary feeding and the multifaceted role of grandmothers in Malawi. Soc Sci Med. 2008;66(5):1095-105.

18. Negin J, Coffman J, Vizintin P, Raynes-Greenow C. The influence of grandmothers on breastfeeding rates: a systematic review. BMC Pregnancy Childbirth. 2016;16:91.

19. Karmacharya C, Cunningham K, Choufani J, Kadiyala S. Grandmothers' knowledge positively influences maternal knowledge and infant and young child feeding practices. Public Health Nutr. 2017;20(12):2114-23.

20. Ferreira TDM, Piccioni LD, Queiroz PHB, Silva EM, Vale IND. Influence of grandmothers on exclusive breastfeeding: cross-sectional study. Einstein (Sao Paulo). 2018;16(4):eA04293.

21. van der Straten A, Ryan JH, Reddy K, Etima J, Taulo F, Mutero P, et al. Influences on willingness to use vaginal or oral HIV PrEP during pregnancy and breastfeeding in Africa: the multisite MAMMA study. J Int AIDS Soc. 2020;23(6):e25536.

22. Baeten JM, Donnell D, Ndase P, Mugo NR, Campbell JD, Wangisi J, et al. Antiretroviral prophylaxis for HIV prevention in heterosexual men and women. N Engl J Med. 2012;367(5):399-410.

23. RTI International. Workshop: Participatory Rapid Qualitative Analysis and Capacity Building2020 20 June 2020. Available from: https://www.rti.org/impact/workshop-participatory-rapid-qualitative-analysis-and-capacity-building.

24. Mudavanhu D, Segalo P, Fourie E. Grandmothers caring for their children orphaned by HIV and AIDS. New Voices Psychol. 2008;4.

25. Rutakumwa R, Zalwango F, Richards E, Seeley J. Exploring the care relationship between grandparents/older carers and children infected with HIV in south-western Uganda: implications for care for both the children and their older carers. Int J Environ Res Public Health. 2015;12(2):2120-34.

26. Koechlin FM, Fonner VA, Dalglish SL, O'Reilly KR, Baggaley R, Grant RM, et al. Values and Preferences on the Use of Oral Pre-exposure Prophylaxis (PrEP) for HIV Prevention Among Multiple Populations: A Systematic Review of the Literature. AIDS Behav. 2017;21(5):1325-35.

27. Montgomery ET, van der Straten A, Chitukuta M, Reddy K, Woeber K, Atujuna M, et al. Acceptability and use of a dapivirine vaginal ring in a phase III trial. AIDS. 2017;31(8):1159-67.

28. Aubel J. Grandmothers Help Prevent Teen Pregnancy during COVID-19 in Senegal: Ahoka: Southern Africa; 2020 [Available from: https://www.ashoka.org/en-za/story/grandmothers-help-prevent-teen-pregnancy-during-covid-19-senegal.

29. Limaye RJ, Rimal RN, Mkandawire G, Kamath V. Tapping Into Traditional Norms for Preventing HIV and Unintended Pregnancy: Harnessing the Influence of Grandmothers (Agogos) in Malawi. Int Q Community Health Educ. 2015;36(1):53-70.

\section{Tables}


Table I

GD conduct and participation across the four participating sites

\begin{tabular}{|c|c|c|c|c|c|c|c|c|c|}
\hline \multirow[t]{2}{*}{ FGD } & \multicolumn{2}{|c|}{$\begin{array}{l}\text { Malawi } \\
\text { (No. of participants) }\end{array}$} & \multicolumn{2}{|c|}{$\begin{array}{l}\text { South Africa } \\
\text { (No. of participants) }\end{array}$} & \multicolumn{2}{|c|}{$\begin{array}{l}\text { Uganda } \\
\text { (No. of participants) }\end{array}$} & \multicolumn{2}{|c|}{$\begin{array}{l}\text { Zimbabwe } \\
\text { (No. of participants) }\end{array}$} & Total \\
\hline & FGD 1 & FGD 2 & FGD 1 & FGD 2 & FGD 1 & FGD 2 & FGD 1 & FGD 2 & \\
\hline
\end{tabular}

\begin{tabular}{|lllllllll|}
\hline Pregnant or breastfeeding women & 8 & 7 & 9 & 6 & 9 & 9 & 7 \\
\hline Male partners of pregnant or breastfeeding women & 6 & 10 & 7 & 5 & 10 & 9 & 9 \\
\hline Grandmothers & 10 & NA & 12 & 8 & 9 & 12 & 8 \\
\hline
\end{tabular}


Demographic information across the four participating sites

\begin{tabular}{|c|c|c|c|c|c|c|c|c|c|c|c|c|}
\hline & \multicolumn{4}{|c|}{ Grandmothers } & \multicolumn{4}{|c|}{ Pregnant and Breastfeeding Women } & \multicolumn{4}{|c|}{$\begin{array}{l}\text { Male Partners of Pregnant and } \\
\text { Breastfeeding Women }\end{array}$} \\
\hline & $\begin{array}{l}\text { Malawi } \\
(\mathrm{N}= \\
10)\end{array}$ & $\begin{array}{l}\text { South } \\
\text { Africa } \\
(\mathrm{N}= \\
20)\end{array}$ & $\begin{array}{l}\text { Uganda } \\
(N=21)\end{array}$ & $\begin{array}{l}\text { Zimbabwe } \\
(\mathrm{N}=17)\end{array}$ & $\begin{array}{l}\text { Malawi } \\
(\mathrm{N}= \\
15)\end{array}$ & $\begin{array}{l}\text { South } \\
\text { Africa } \\
(\mathrm{N}= \\
15)\end{array}$ & $\begin{array}{l}\text { Uganda } \\
(N=18)\end{array}$ & $\begin{array}{l}\text { Zimbabwe } \\
(\mathrm{N}=17)\end{array}$ & $\begin{array}{l}\text { Malawi } \\
(\mathrm{N}= \\
16)\end{array}$ & $\begin{array}{l}\text { South } \\
\text { Africa } \\
(\mathrm{N}= \\
12)\end{array}$ & $\begin{array}{l}\text { Uganda } \\
(N=19)\end{array}$ & $\begin{array}{l}\text { Zimbabw } \\
(\mathrm{N}=16)\end{array}$ \\
\hline Mean Age (Years) & $\begin{array}{l}50.6 \\
(39- \\
69)\end{array}$ & $\begin{array}{l}54.9 \\
(36- \\
67)\end{array}$ & $\begin{array}{l}47.1 \\
(37- \\
63)\end{array}$ & $\begin{array}{l}46 \\
(36-63)\end{array}$ & $\begin{array}{l}26.7 \\
(21- \\
34)\end{array}$ & $\begin{array}{l}28.0 \\
(22- \\
40)\end{array}$ & $\begin{array}{l}27.2 \\
(19- \\
40)\end{array}$ & $\begin{array}{l}26.6 \\
(19-38)\end{array}$ & $\begin{array}{l}30.2 \\
(19- \\
53)\end{array}$ & $\begin{array}{l}33.0 \\
(27- \\
49)\end{array}$ & $\begin{array}{l}32.4 \\
(23- \\
54)\end{array}$ & $\begin{array}{l}27.0 \\
(19-45)\end{array}$ \\
\hline $\begin{array}{l}\text { Secondary } \\
\text { education complete }\end{array}$ & $\begin{array}{l}1 \\
(10 \%)\end{array}$ & $\begin{array}{l}6 \\
(30 \%)\end{array}$ & $6(29 \%)$ & $6(35 \%)$ & $\begin{array}{l}6 \\
(40 \%)\end{array}$ & $\begin{array}{l}11 \\
(73 \%)\end{array}$ & $4(22 \%)$ & $12(71 \%)$ & $\begin{array}{l}6 \\
(38 \%)\end{array}$ & $\begin{array}{l}8 \\
(67 \%)\end{array}$ & $9(47 \%)$ & $12(75 \%)$ \\
\hline $\begin{array}{l}\text { Earning own } \\
\text { income (\#) }\end{array}$ & $\begin{array}{l}7 \\
(70 \%)\end{array}$ & $\begin{array}{l}3 \\
(15 \%)\end{array}$ & $\begin{array}{l}19 \\
(91 \%)\end{array}$ & $11(65 \%)$ & $\begin{array}{l}9 \\
(60 \%)\end{array}$ & 0 & $\begin{array}{l}12 \\
(71 \%)\end{array}$ & $6(35 \%)$ & $\begin{array}{l}13 \\
(81 \%)\end{array}$ & $\begin{array}{l}4 \\
(33 \%)\end{array}$ & $\begin{array}{l}17 \\
(90 \%)\end{array}$ & $14(88 \%)$ \\
\hline \multicolumn{13}{|l|}{ Religion } \\
\hline Christian & $\begin{array}{l}10 \\
(100 \%)\end{array}$ & $\begin{array}{l}19 \\
(95 \%)\end{array}$ & $\begin{array}{l}16 \\
(76 \%)\end{array}$ & $16(94 \%)$ & $\begin{array}{l}14 \\
(93 \%)\end{array}$ & $\begin{array}{l}15 \\
(100 \%)\end{array}$ & $\begin{array}{l}17 \\
(94 \%)\end{array}$ & $17(100 \%)$ & $\begin{array}{l}15 \\
(94 \%)\end{array}$ & $\begin{array}{l}9 \\
(75 \%)\end{array}$ & $\begin{array}{l}14 \\
(74 \%)\end{array}$ & $15(94 \%)$ \\
\hline Muslim & 0 & 0 & $5(24 \%)$ & 0 & $1(7 \%)$ & 0 & $1(6 \%)$ & 0 & $1(6 \%)$ & $\begin{array}{l}1 \\
(8 \%)\end{array}$ & $5(26 \%)$ & 0 \\
\hline \multicolumn{13}{|l|}{ Marital status } \\
\hline Single & 0 & $\begin{array}{l}12 \\
(60 \%)\end{array}$ & $2(10 \%)$ & 0 & 0 & $\begin{array}{l}14 \\
(93 \%)\end{array}$ & $1(6 \%)$ & 0 & $1(6 \%)$ & $\begin{array}{l}11 \\
(92 \%)\end{array}$ & $3(17 \%)$ & 0 \\
\hline Married & $\begin{array}{l}5 \\
(50 \%)\end{array}$ & $\begin{array}{l}3 \\
(15 \%)\end{array}$ & $7(33 \%)$ & $13(77 \%)$ & $\begin{array}{l}14 \\
(93 \%)\end{array}$ & $1(7 \%)$ & $\begin{array}{l}16 \\
(89 \%)\end{array}$ & $16(94 \%)$ & $\begin{array}{l}15 \\
(94 \%)\end{array}$ & $\begin{array}{l}1 \\
(8 \%)\end{array}$ & $\begin{array}{l}15 \\
(83 \%)\end{array}$ & $15(94 \%)$ \\
\hline $\begin{array}{l}\text { Separated/ } \\
\text { divorced }\end{array}$ & $\begin{array}{l}2 \\
(20 \%)\end{array}$ & $\begin{array}{l}3 \\
(15 \%)\end{array}$ & $9(43 \%)$ & 0 & $1(7 \%)$ & 0 & $1(6 \%)$ & $1(6 \%)$ & 0 & 0 & 0 & 0 \\
\hline Widowed & $\begin{array}{l}3 \\
(30 \%)\end{array}$ & $\begin{array}{l}2 \\
(10 \%)\end{array}$ & $3(14 \%)$ & $4(24 \%)$ & 0 & 0 & 0 & 0 & 0 & 0 & 0 & 0 \\
\hline \multicolumn{13}{|l|}{$\begin{array}{l}\text { Household } \\
\text { composition }\end{array}$} \\
\hline Lives alone & 0 & 0 & $1(5 \%)$ & 0 & 0 & $1(7 \%)$ & $1(6 \%)$ & 0 & 0 & $\begin{array}{l}2 \\
(17 \%)\end{array}$ & $1(5 \%)$ & $1(6 \%)$ \\
\hline $\begin{array}{l}\text { Spouse/primary } \\
\text { partner }\end{array}$ & $\begin{array}{l}5 \\
(50 \%)\end{array}$ & $\begin{array}{l}4 \\
(20 \%)\end{array}$ & $5(24 \%)$ & 12 (71\%) & $\begin{array}{l}13 \\
(87 \%)\end{array}$ & $\begin{array}{l}3 \\
(20 \%)\end{array}$ & $\begin{array}{l}15 \\
(83 \%)\end{array}$ & $16(94 \%)$ & $\begin{array}{l}15 \\
(94 \%)\end{array}$ & $\begin{array}{l}4 \\
(33 \%)\end{array}$ & $\begin{array}{l}15 \\
(79 \%)\end{array}$ & $15(94 \%)$ \\
\hline $\begin{array}{l}\text { Mother and/or } \\
\text { father }\end{array}$ & $\begin{array}{l}2 \\
(20 \%)\end{array}$ & $\begin{array}{l}3 \\
(15 \%)\end{array}$ & $1(5 \%)$ & $1(6 \%)$ & $1(7 \%)$ & $\begin{array}{l}5 \\
(33 \%)\end{array}$ & $1(6 \%)$ & $1(6 \%)$ & 0 & $\begin{array}{l}7 \\
(58 \%)\end{array}$ & $1(5 \%)$ & $2(13 \%)$ \\
\hline Sibling(s) & $\begin{array}{l}1 \\
(10 \%)\end{array}$ & $\begin{array}{l}5 \\
(25 \%)\end{array}$ & $3(14 \%)$ & $1(6 \%)$ & $\begin{array}{l}3 \\
(20 \%)\end{array}$ & $\begin{array}{l}8 \\
(53 \%)\end{array}$ & $1(6 \%)$ & 0 & $\begin{array}{l}2 \\
(13 \%)\end{array}$ & $\begin{array}{l}3 \\
(25 \%)\end{array}$ & $4(21 \%)$ & $2(13 \%)$ \\
\hline Grandparent(s) & 0 & $\begin{array}{l}1 \\
(5 \%)\end{array}$ & 0 & $1(3 \%)$ & 0 & $1(7 \%)$ & 0 & 0 & $\begin{array}{l}2 \\
(13 \%)\end{array}$ & $\begin{array}{l}2 \\
(17 \%)\end{array}$ & 0 & 0 \\
\hline Other relative(s) & $\begin{array}{l}1 \\
(10 \%)\end{array}$ & $\begin{array}{l}5 \\
(25 \%)\end{array}$ & $3(14 \%)$ & $1(6 \%)$ & $1(7 \%)$ & $1(7 \%)$ & 0 & $4(24 \%)$ & $\begin{array}{l}3 \\
(19 \%)\end{array}$ & $\begin{array}{l}1 \\
(8 \%)\end{array}$ & $1(5 \%)$ & 0 \\
\hline Child(ren) & $\begin{array}{l}8 \\
(80 \%)\end{array}$ & $\begin{array}{l}16 \\
(80 \%)\end{array}$ & $\begin{array}{l}18 \\
(86 \%)\end{array}$ & 13 (77\%) & $\begin{array}{l}11 \\
(73 \%)\end{array}$ & $\begin{array}{l}8 \\
(53 \%)\end{array}$ & $\begin{array}{l}11 \\
(61 \%)\end{array}$ & $14(82 \%)$ & $\begin{array}{l}13 \\
(81 \%)\end{array}$ & $\begin{array}{l}1 \\
(8 \%)\end{array}$ & $\begin{array}{l}11 \\
(58 \%)\end{array}$ & $10(63 \%)$ \\
\hline Grandchild(ren) & $\begin{array}{l}6 \\
(60 \%)\end{array}$ & $\begin{array}{l}13 \\
(65 \%)\end{array}$ & $\begin{array}{l}10 \\
(48 \%)\end{array}$ & $2(12 \%)$ & $1(7 \%)$ & 0 & 0 & 0 & 0 & 0 & 0 & 0 \\
\hline Other & 0 & $\begin{array}{l}1 \\
(5 \%)\end{array}$ & 0 & $1(6 \%)$ & $\begin{array}{l}3 \\
(20 \%)\end{array}$ & 0 & $1(6 \%)$ & $2(12 \%)$ & 0 & $\begin{array}{l}1 \\
(8 \%)\end{array}$ & 0 & 0 \\
\hline $\begin{array}{l}\text { Adult Family } \\
\text { Member }\end{array}$ & $\begin{array}{l}3 \\
(30 \%)\end{array}$ & $\begin{array}{l}13 \\
(65 \%)\end{array}$ & & $4(24 \%)$ & $\begin{array}{l}4 \\
(27 \%)\end{array}$ & $\begin{array}{l}10 \\
(67 \%)\end{array}$ & $1(6 \%)$ & $5(29 \%)$ & $\begin{array}{l}7 \\
(44 \%)\end{array}$ & $\begin{array}{l}7 \\
(58 \%)\end{array}$ & $6(32 \%)$ & $4(25 \%)$ \\
\hline
\end{tabular}


Pregnant and breastfeeding women's $(\mathrm{N}=65)$ views on who has the most influence during pregnancy and breastfeeding besides themselves

\begin{tabular}{|c|c|c|c|c|c|c|c|c|}
\hline \multirow[t]{2}{*}{ Influencer* } & \multicolumn{4}{|c|}{ Pregnancy (65 responses) } & \multicolumn{4}{|c|}{ Breastfeeding (48 responses)^^} \\
\hline & Malawi & $\begin{array}{l}\text { South } \\
\text { Africa }\end{array}$ & Uganda & Zimbabwe & Malawi & $\begin{array}{l}\text { South } \\
\text { Africa }\end{array}$ & Uganda & Zimbabwe \\
\hline $\begin{array}{l}\text { The father of } \\
\text { their baby }\end{array}$ & $9(60 \%)$ & $4(27 \%)$ & $11(61 \%)$ & $15(88 \%)$ & $\begin{array}{l}11 \\
(92 \%)\end{array}$ & $2(20 \%)$ & $8(53 \%)$ & $9(82 \%)$ \\
\hline Their mother & $2(13 \%)$ & $6(40 \%)$ & $2(11 \%)$ & 0 & $1(8 \%)$ & $4(40 \%)$ & $3(20 \%)$ & $1(9 \%)$ \\
\hline $\begin{array}{l}\text { Their mother-in- } \\
\text { law }\end{array}$ & $1(7 \%)$ & 0 & $1(6 \%)$ & 0 & - & - & - & - \\
\hline Their doctor & $3(20 \%)$ & 0 & $3(17 \%)$ & $2(12 \%)$ & 0 & 0 & $4(27 \%)$ & 0 \\
\hline Their nurse & - & - & - & - & 0 & $2(20 \%)$ & 0 & 0 \\
\hline Other & 0 & $4^{\wedge}(27 \%)$ & 0 & 0 & 0 & $\star \star 2(20 \%)$ & 0 & $1^{\wedge}(9 \%)$ \\
\hline No response & 0 & $1(7 \%)$ & $1(6 \%)$ & 0 & - & - & - & - \\
\hline \multicolumn{9}{|c|}{ * Participants were permitted to choose one option } \\
\hline \multicolumn{9}{|c|}{$\Delta$ Only 48 women were currently breastfeeding or had ever breastfed } \\
\hline
\end{tabular}


Table IV

Grandmother advice and support provided during pregnancy and/or breastfeeding as described by participants during FGDs

Domains

Exemplary Quote

Grandmothers' advisory roles

Diet

When our partners are pregnant especially for the first time, we usually go and consult our parents to know what foods a pregnant woman is supposed to eat, how you have to handle her so that the pregnancy remains well, and she is also healthy. [Emma, Male partner, 23, Uganda]

I come in as an experienced mother because I have been pregnant before. So I can safely advise and tell her that the food she is eating can cause something else or if she does something it would result in what. [Mbuya Netsai, Grandmother, 42, Zimbabwe]

Health seeking She treat her baby like a doll. I know more; so, I am the one who is supposed to determine that she must take the baby to the clinic

behaviour or say no here you must take a baby to the clinic not to the doctor, but to the clinic. [Dineo, Grandmother, 58 , South Africa]

Cultural practices

So, there are some of the things that she will go and learn concerning her health, and other cultural practices that are done so that the baby will not grow up as a feeble. I heard that our in-laws will teach their daughter what to do so that the baby will grow healthy. [Pizza, Male partner, 28, Zimbabwe]

Sexual matters $\quad$ So while there is this saying that men cannot restrain themselves, there is this sexual practice called "Ukusoma," [thigh sex], a man ejaculate outside not inside the womb. And we grew up knowing that as woman you should do that type of sex after you have delivered, your parents tell you. That is why you have to deliver at your parents' place so that your mother can be open and guide you. Then after delivery you will go back to your marriage home, after three to six months. [Guest, Grandmother, 67, South Africa]

I tell my pregnant children to stop having sex at 8 months...I have changed from 7 to 8 months. [Naphiri, 69, Grandmother, Malawi]

Let me add to what [Naphiri] has said, the reason why they say we stop [sex] at 8 months is that, these days there are a lot of infections, and if you tell a husband to stop sex with his wife at 7 months and yet the husband still has the desire to have sex, he will go out and find an extra marital sexual partner and have unprotected sex...it is not possible for a couple to stay without having sex for a month ,they can have sex once or twice a week.....so as the husband is having sex with other women, he easily contract infections and also infect the pregnant woman. [Evelyn, Grandmother, 47, Malawi]

Maternal

A mother [grandmother] because you have to tell your daughter that now that you are pregnant you should not walk about in the

Behaviour streets, you should not stand by the gate, you should not eat standing, such things. [Zintle, Grandmother, 63, South Africa]

With me already I make my own decisions, but sometimes my elder aunt tells me I have to do this or I don't have to do that. Maybe after you have had a child your friends should not visit you or you should not go and have sex with your boyfriend, you should not stand by the gate or by the door. You must stay in a room and get out only when you go to the toilet, so those are the decisions they make for me at home. [Red, Breastfeeding woman, 30, South Africa].

When our daughter/daughter in law is pregnant we as parents make decisions for them. We can tell them that because they are pregnant they should not sit or stand on the door. They find a chair and sit away from a door. This means that when a baby is being born the baby can't delay or stuck on the door [cervix] these are parents' beliefs. [Tadala, Grandmother, 40, Blantyre]

Grandmothers' supportive roles

Financial/Resource I then go back home and in case my husband has no money to look after me I then go to my mother-in-law and she will provide anything that I might need. Yes, health workers will provide the health care and then if my husband fails to get what to eat I then go to my mother-in-law for help. [Agatha, Pregnant woman, 21, Uganda]

Emotional Most times when you are worried when you are pregnant and the worries are coming because of the husband you are with, you go and share your worries with your mother because she is the one you are close to. [Lucy, Breastfeeding women, 29, Malawi]

Instrumental I I think this thing depends on my ability when my daughter goes out with a boyfriend; I must check her when she leaves, call her and tell her to take her pills with [her]. I love her and concerned about her health while pregnant so I have to always ask her if she has taken her pills. [Apple, Grandmother, 54, South Africa] 
Grandmother views on the ring and oral PrEP for pregnant and breastfeeding women

\begin{tabular}{ll}
$\begin{array}{l}\text { Product related } \\
\text { attribute/theme }\end{array}$ & Ring \\
\hline $\begin{array}{l}\text { Dosage } \\
\text { form/familiarity } \\
\text { and comfort }\end{array}$ & $\begin{array}{l}\text { Since it is a new thing that is being introduced, when she } \\
\text { starts using it, will she feel comfortable having it inserted, is } \\
\text { it not painful the moment she starts using it? [Mbuya } \\
\text { Rutendo, 44, Zimbabwe] }\end{array}$ \\
& $\begin{array}{l}\text { Isn't it's big? I just wondered if our vaginas are big like the } \\
\text { ring. Will the ring not enlarge the vagina? [Mbuya vaPinky, } \\
\text { 48, Zimbabwe] }\end{array}$ \\
$\begin{array}{ll}\text { Dosage form/ } \\
\text { mechanism of } \\
\text { action }\end{array}$ & $\begin{array}{l}\text { I prefer the ring because it stays in there, it's safer, and you } \\
\text { might have side effects for both a pregnant mother and the } \\
\text { foetus. [Yellow, 43, South Africa] }\end{array}$ \\
$\begin{array}{ll}\text { Dosage } \\
\text { form/User } \\
\text { burden }\end{array}$ & $\begin{array}{l}\text { Because if she inserts the ring, she will not forget like she } \\
\text { will when taking the pill. She might take them and } \\
\text { sometimes forget. Or she might go for a funeral and you will }\end{array}$ \\
hear her say that, "I forgot my pills." [Gogo Munyemba, 42,
\end{tabular}

Discretion of

use/HIV stigma

Discretion of use/ gendered relationships

Speaking my own opinion, the ring will be preferred because some husbands oppress their wives in these marriages. So the ring would be preferred the most because some women will just use the ring without their partner's knowledge. This program is very good because we can see HIV being reduced in Zimbabwe. [Mbuya Rarara, 36, Zimbabwe]

I think some people will use it discreetly because men are always against whatever is implemented. One can say "why don't you trust me? Do you think I have so many other sexual partners?" So some women will use it discreetly. [Mary, 54, Uganda]

Safety/Mother I do not know if it does not have some side effects that can or baby affect the baby. [Mbuya vaPinky, 48, Zimbabwe]

\section{Oral PrEP}

Maybe most of all have accepted that HIV is an existing condition and it affects everyone so a person who will say "HIV," no that person is behind times because all of us are HIV and taking pills. So I think pills are acceptable I don't think anyone will have a problem while pregnant. [Guest, 67, South Africa]

I am just wondering, like if I took it yesterday and today I forget to take it, how long does it take to work in my body, if on the day I forget it I engage in sex wouldn't I be putting myself at risk? [Mamorena, 58, South Africa]

I don't agree with the pill, it is the vaginal ring only. One can easily forget to take the pill. [Rose, 46, Uganda]

I think some people might prefer the ring unlike the pill because she might find it hard to take them when surrounded by people. She will fear that people will think she will be using an ARV to treat HIV, so it may be difficult for her to explain to people about the pill she is taking. [Mbuya Shava, 43, Zimbabwe]

No because the bitter medicine may interfere with the baby in the womb and lead to a miscarriage. [Zaina, 42, Uganda]

My concern is that the pill could affect the baby inside the womb. The baby may get wounds and it is the pills which burnt her/him. [Agatha, 61, Uganda]

For bitter medicine it depends on the number of months, during the first trimester one is not accepted to take bitter things but if the pregnancy is four months and at eight months one must take fansidar which is bitter but it is a prevention against malaria that could affect the baby. So, it depends on the drug and how the health worker understands it and the months of pregnancy. [Mastula, 38, Uganda

Safety/during What happens when a pregnant woman with a ring gets into

labour labor and wants to deliver the baby there and when the ring is still in place? [Mbuya Zvakanaka, 63, Zimbabwe]

The baby might react to the medicine from the ring during delivery, and it may affect her. [Gogo Tadiwa, 40, Zimbabwe]

I am afraid that maybe the baby might put its little head inside the ring. [Mbuya Muti, 62, Zimbabwe] 